\title{
Weryfikacja systemu do planowania leczenia w brachyterapii metodą TLD
}

\section{Verification of the treatment planning system for brachytherapy with the use of TLD technique}

\author{
Natalia Matuszak ${ }^{1}$ \\ ${ }^{1}$ Katedra i Zakład Elektroradiologii, Uniwersytet Medyczny im. Karola Marcinkowskiego, Poznań
}

\section{Streszczenie}

Zjawisko termoluminescencji jest jedną z fundamentalnych metod luminescencji. Po napromienieniu, luminofor uwalnia energię zgromadzoną w postaci światła, o intensywności proporcjonalnej do pochłoniętej dawki. Emisja światła jest możliwa po uprzedniej ekspozycji promieniowaniem jonizującym bądź UV, a następnie wygrzaniu. Krzywe termoluminescencyjne obrazują efekt liniowego wzrostu temperatury, którym jest rejestracja ilości emitowanych kwantów luminescencji. Miarą pochłoniętej dawki jest amplituda piku równa scałkowanej powierzchni pod krzywą TL.

Część fizyczną badań, obejmującą pomiary termoluminescencyjne przeprowadzono w Zakładzie Fizyki Jądrowej i Jej Zastosowań Uniwersytetu Śląskiego w Katowicach. Wszystkie czynności eksperymentalne dotyczące brachyterapii i tym samym wymagające użycia pożądanej aparatury zrealizowano w Zakładzie Radioterapii Katowickiego Centrum Onkologii.

Weryfikacja opierała się na korelacji wyników dawek z planów leczenia, opartych na odmiennych algorytmach formalizujących obliczenia rozkładu dawki, z dawkami uzyskanymi na drodze pomiaru termoluminescencyjnego.

Analiza wykazała, że metoda dozymetrii termoluminescencyjnej może być wykorzystana do weryfikacji dawek generowanych przez system planujący leczenie. Zgodność wyników jest możliwa przy uwzględnieniu wszystkich parametrów fizycznych pomiaru oraz warunków biologicznych.

\footnotetext{
Abstract the TL curve

Thermoluminescence is one of the fundamental luminescence methods. After irradiation, phosphor cumulates energy and then emits it as light with intensity proportional to absorbed dose. Emission of light follows prior exposure by ionization radiation or ultraviolet radiation and heating. Thermoluminescence curves are the result of a linear increase of temperature and show the amount of emitted luminescence quants. The dose absorbed is expressed by the peak amplitude which is equal to the integrated area under 
Physical part of the study which included thermoluminescence measurements was performer at the Department of Nuclear Physics and its Applications, University of Silesia in Katowice. All experimental works concerned brachytherapy, medical devices and software were conducted at the Department of Radiotherapy of Cancer Center in Katowice.

Verification was based on the correlation of doses from differential algorithms formalizing dose distribution in treatment planning system with doses of thermoluminescence measurements.

Analysis showed that the TLD technique can be used for verification of doses generated by a treatment planning system. Consistency of results can be achieved with all physical parameters of measurement and biological conditions taken into consideration.

Słowa kluczowe: dozymetria termoluminescencyjna; system do planowania leczenia; brachyterapia; dawka

Keywords: thermoluminescence dosimetry; treatment planning system; brachytherapy; dose

\section{Wstęp}

Luminescencją nazywamy zjawisko emisji świetlnej w wyniku dostarczenia energii cieplnej po ekspozycji na promieniowanie jonizujące. Czynnikiem wzbudzającym efekt świetlny w termoluminescencji jest temperatura. Procesy składające się na zjawisko TL (ang. Thermoluminescence), bazują na teorii pasmowej kryształów dielektryka i najlepiej zobrazować je opierając się na ich modelu energetycznym. Temperatura, do której należy ogrzać materiał, aby widoczne stały się jego efekty termoluminescencyjne to zwykle $200^{\circ} \mathrm{C}$. Każdy materiał TL charakteryzuje krzywa wyświecania tzw. krzywa TL, składająca się z kilku pików. Otrzymujemy ją w wyniku rejestracji liczby emitowanych kwantów w funkcji wzrostu temperatury. Piki dozymetryczne dostrzegalne są w zakresie $180-250^{\circ} \mathrm{C}$. Najczęściej w analizowanym zakresie temperatur 50 $-350^{\circ} \mathrm{C}$ wyróżniamy sześć pików. Ponieważ trzy pierwsze nie są uwzględniane do celów dozymetrycznych, stąd w wyniku anilacji przeprowadzamy ich redukcję. Najcenniejsze informacje niosą pik czwarty oraz piąty. Ich prezentacja służy do pomiaru dawek [1].

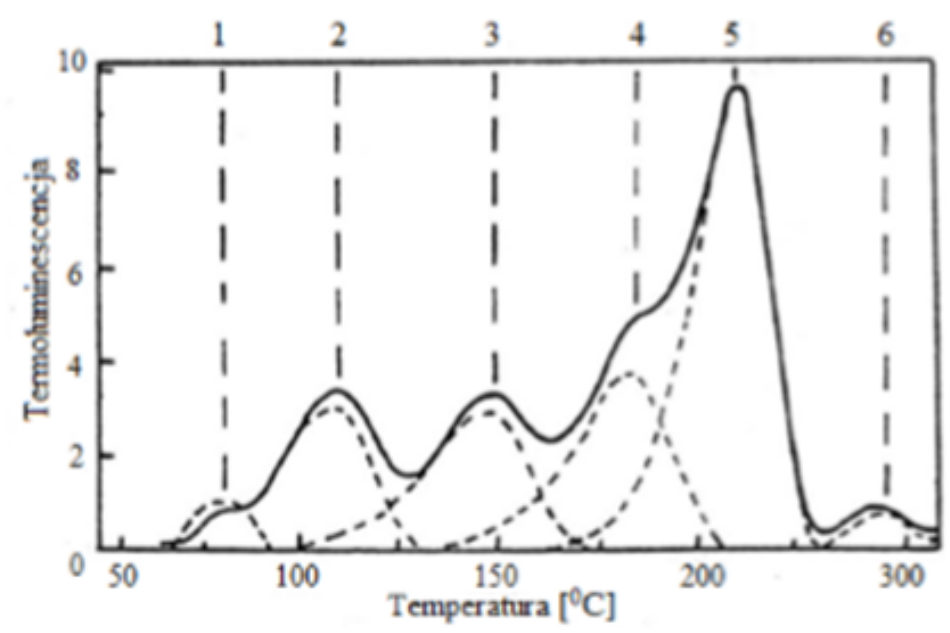

Rycina 1. Krzywa wyświecania LiF:Mg,Ti z uwzględnieniem położenia charakterystycznych sześciu pików, zarejestrowanych w zakresie od około $70^{\circ} \mathrm{C}$ do $135^{\circ} \mathrm{C}$. Aby dostrzegalne były efekty termoluminescencji należy ogrzać detektor do temperatury ok. $200^{\circ} \mathrm{C}$. Piki dozymetryczne tj. pik czwarty i piąty, pojawiają się w zakresie temperatur $180-250^{\circ} \mathrm{C}$. Są one najistotniejsze do celów badań, w przeciwieństwie do trzech pierwszych pików.

O przydatności materiałów TL w medycznych aplikacjach decyduje wartość ekwiwalentu tkankowego zbliżona do tkanki ludzkiej. Takie kryterium spełniają fluorki litu, co wyjaśnia ich użycie do pomiarów dawek. Fluorki litu domieszkowane magnezem i tytanem (LiF:Mg,Ti) wykazują wysoką czułość dla ogólnych zastosowań, niskie tło oraz opór przed warunkami środowiskowymi. Ich niska liczba atomowa powoduje brak 
znaczących rozbieżności odpowiedzi TL na dawki promieniowania fotonowego, w stosunku do odpowiedzi tkanek miękkich. Jest to istotna informacja w przeznaczeniu fluorków litu do dozymetrii pomiarowej [2].

Promieniowanie jonizujące jest coraz częściej wykorzystywane w medycynie w zakresie leczenia zmian nowotworowych. Ze względu na lokalizację źródła, terapię promieniowaniem jonizującym możemy podzielić na brachyterapię i teleradioterapię. Brachyterapia jest jedną z metod radioterapii nowotworów, która wykorzystuje energię fotonów lub cząstek, pochodzącą z rozpadu izotopów promieniotwórczych umieszczanych w guzie lub w jego bliskim sąsiedztwie [3]. W brachyterapii źródło promieniotwórcze jest umieszczane w tzw. aplikatorze, czyli plastikowej rurce, wprowadzanej bezpośrednio w okolicę guza. Poprzez kontakt źródła promieniotwórczego z guzem, brachyterapia daje możliwość precyzyjnej kumulacji wysokiej dawki promieniowania w bliskim otoczeniu izotopu. Obecnie najczęściej używane są źródła irydu-192, cezu-137 oraz jodu-125 [4]. Ze względu na lokalizację izotopu, brachyterapię dzielimy na śródjamową oraz śródtkankową, która dodatkowo dzieli się na wewnątrzprzewodową, wewnątrzjamową, wewnątrznaczyniową oraz powierzchniową. Brachyterapię można też skategoryzować na podstawie stosowanych wielkości mocy dawki, a więc i czasu aplikacji. Wyróżniamy niskie moce dawki LDR (ang. Low Dose Rate) o,4 2Gy/h, średnie moce dawki MDR (ang. Medium Dose Rate) 2 - 12Gy/h oraz wysokie moce dawki HDR (ang. High Dose Rate) powyżej 12Gy/h. Leczenie za pomocą brachyterapii jest procesem kilkuetapowym. Dobrany dla danego pacjenta aplikator wprowadzany jest bezpośrednio do zmiany nowotworowej lub do najbliższego jej sąsiedztwa [4]. Aplikator nie zawiera źródeł promieniotwórczych i nie stanowi zagrożenia radiologicznego. Komputerowy system planowania leczenia TPS (ang. Treatment Planning System) odpowiada za odtworzenie przestrzennego rozmieszczenia źródeł, co jest początkiem procesu optymalizacji. Jego główną ideą jest określenie optymalnego rozkładu dawki, który zakłada odpowiednio wysoką dawkę do zniszczenia zmiany nowotworowej oraz jak najniższą dawkę w obszarze narządów krytycznych i tkanek zdrowych. Ponadto musi być spełnione kryterium jednorodności rozkładu dawki w obszarze tarczowym [5,6]. Bardzo ważne jest określenie dawek, jakie podczas napromieniania otrzymają narządy szczególnie wrażliwe na promieniowanie (np. pęcherz, odbytnica). Ogólny plan leczenia dotyczy więc objęcia zasięgiem aplikatora obszaru guza, stabilizacji aplikatorów, rekonstrukcji 3D oraz określenia dawki obejmującej guz $\mathrm{z}$ odpowiednim marginesem.

\section{Cel}

Zasadniczym celem pracy było przeprowadzenie za pośrednictwem techniki TLD (ang. Thermoluminescent Dosimetry), weryfikacji dozymetrycznej systemu planującego proces leczenia w brachyterapii. Ocena dozymetryczna polegała na uzyskaniu wyników dawek z planów, opartych na odmiennych algorytmach formalizujących obliczenia rozkładu dawki, a następnie powiązaniu ich $\mathrm{z}$ wynikami pomiaru termoluminescencyjnego. Zadania szczegółowe obejmują:

- przeprowadzenie termoluminescencyjnego cyklu pomiarowego, zakończonego obliczeniami dawki dla dwudziestu czterech detektorów MTS,

- wykorzystanie aplikatora ginekologicznego w celu połączenia idei TL z brachyterapią,

- zapis wartości dawek zaplanowanych przez system leczenia, w oparciu o trzy formalizmy definiujące ich rozkład, tj. TG-43, TG-186, TG-186A,

- $\quad$ weryfikacje dozymetryczną dawek TL osiągniętych eksperymentalnie z dawkami wygenerowanymi przez system planowania leczenia w brachyterapii.

\section{Material i metoda}

\section{- Pomiar dawki techniką TL}

Do realizacji badań, wykorzystano 24 wysokoczułe detektory MTS na bazie fluorku litu o wymiarach o,3 x 0,3 x 0,9mm³. Poza detektorami, na aparaturę pomiarową składał się również zestaw umożliwiający odczyt dawek tzw. czytnik. 
Przebieg pomiarów, przeprowadzany był na drodze kilku etapów:

(1) anilacja detektorów,

(2) ekspozycja na promieniowanie,

(3) odczyt w kontrolowanych warunkach w czytniku laboratoryjnym.

Optymalne warunki procesu wygrzewania detektorów (tzw. anilacja przedekspozycyjna) obejmowały godzinne grzanie $\mathrm{w}$ piecu $\mathrm{w}$ temperaturze $400^{\circ} \mathrm{C}$ oraz dwukrotnie dłuższe $\mathrm{w} 100^{\circ} \mathrm{C}$. Wygrzewanie przeprowadzono w sterowanych mikroprocesorowo piecach o stabilności $\pm 1^{\circ} \mathrm{C}$. Detektory umieszczano na cienkiej płytce aluminiowej, w piecu o zadanej temperaturze. Po upływie przewidzianego czasu wygrzewania, płytkę z detektorami wyjmowano z pieca i umieszczano na grubym bloku aluminiowym, w celu szybkiego schłodzenia detektorów do temperatury pokojowej. Przeprowadzenie anilacji przedekspozycyjnej miało na celu redukcję pików niskotemperaturowych, które nie są pożądane do celów dozymetrycznych. Po wygrzaniu, detektory poddano napromienieniu. Kalibracja obejmowała naświetlenie ich wiązką promieniowania pochodzącą ze źródła Cs-137. Źródło Cs-137 jest w posiadaniu Zakładu Fizyki Jądrowej i jej Zastosowań Instytutu Fizyki w Katowicach. Wyznaczenie stosunku odpowiedzi TL na znaną dawkę tj. 2Gy, przy ustalonym polu napromieniania do tej dawki, opisywane jest zależnością [1]:

$$
K=\frac{\left(T L_{\alpha}-T L_{\beta}\right)}{D}
$$

gdzie:

$\mathrm{TL}_{\alpha}$ - średnia z odczytu partii detektorów naświetlanych w powtarzalnych warunkach,

$\mathrm{TL}_{\beta}$ - średnia z odczytu tła,

D- dawka użyta do kalibracji

Po naświetleniu, dokonuje się odczytu detektorów. Zestawiając średnią arytmetyczną odczytów dla całej partii z wynikiem konkretnego detektora otrzymujemy wartość indywidualnego współczynnika czułości tzw. IRF (ang. Individual Reference Factor) niezbędnego do przeliczeń na wartości w jednostkach dawek [Niewiadomski, 1991].

$$
K_{\text {in }}=\frac{T L_{S R}}{T L_{I N D}}
$$

gdzie:

$\mathrm{TL}_{\mathrm{SR}}$ - średnia odczytów całej partii detektorów,

$\mathrm{TL}_{\mathrm{IND}}-$ wynik odczytu indywidualnego detektora.

\section{- Pomiar dawki poprzez TPS}

Podstawądrugiegoetapu częścidoświadczalnejbyłytrzyplanyleczeniazoptymalizowanezapomocąróżnych algorytmów do planowania leczenia w brachyterapii. Użyto tych samych detektorów termoluminescencyjnych TLD-100, po osiem z przeznaczeniem do jednego planu. W przypadku przeprowadzenia kolejnych ekspozycji, nowy wynik odczytu stanowił wielokrotność danych już indywidualnych współczynników czułości. Pierwszy z planów podlegał formalizmowi TG-43 a następne TG-186 z różnym uwzględnieniem wody jako ośrodka. Plan leczenia zdefiniowany zgodnie z algorytmem TG-43 zakładał, że ośrodek, w którym rozchodzi się promieniowanie tj. woda $\mathrm{z}$ aplikatorem, przyjmuje gęstość $1,00 \mathrm{~g} / \mathrm{cm}^{3}$. Gęstość aplikatora nie była jednak równoważna gęstości wody i wynosiła 1,29 g/ $\mathrm{cm}^{3}$. Algorytm TG-186 również zakładał jednakową gęstość dla wody i aplikatora, jednak cechowała go większa dokładność. TG-43 pomija wpływ tkanki, niejednorodność 
aplikatora oraz określone wymiary pacjentów. Obliczenia dawki przy użyciu formalizmu TG-43 dokonuje się wokół pojedynczego, centralnie umieszczonego źródła w kulistym fantomie wodnym [7-15]. Według założeń TG-186, dawki są wrażliwe na przekrój wspólnego oddziaływania woksel po wokselu, czyli w każdym elemencie objętości tkanki [16]. Formalizm, którym posłużono się do opisu trzeciego planu leczenia określono mianem TG-186A z racji uwzględnionej gęstości aplikatora w planie leczenia.

Brachyterapia była prowadzona przy użyciu aparatu terapeutycznego do zdalnej aplikacji źródła, tzw. flexitronu HDR, ze źródłem Ir-192. Pomysł realizacji eksperymentu opierał się na umiejscowieniu detektorów na aplikatorze, w równych odstępach, po przeciwległych stronach aplikatora (umownie nazwanych jako „A” i „B”). Na każdej z dwóch stron aplikatora znajdowały się cztery detektory rozmieszczone co $2 \mathrm{~cm}$, od pozycji $60 \mathrm{~mm}$ do $120 \mathrm{~mm}$ na podziałce aplikatora. Aplikatorem w brachyterapii nazywamy implantowany do ciała pacjenta układ (rurka, dren), do którego wprowadzane jest źródło promieniotwórcze [17]. Na potrzeby prowadzonych badań wykorzystano dopochwowy aplikator wielokanałowy CT/ MR (ang. Computed Tomography/ Magnetic Resonance). Realizuje on brachyterapię dopochwową m.in. w leczeniu raka trzonu macicy. Aplikator podłączono w sposób, w jaki jest zaadaptowany jest podczas seansu terapeutycznego $\mathrm{z}$ pacjentem, zgodnie z techniką remote afterloading. Technika ta polega na umieszczeniu w jamach ciała, (także w tkankach lub na powierzchni skóry) aplikatorów bez źródeł radioaktywnych, lecz z odpowiednimi prowadnicami, tzn. rurkami z metalu lub plastiku. Następnie w sposób mechaniczny, wprowadza się do nich źródła radioaktywne [4]. Dzięki osobno ładowanym kanałom zwiększa się możliwość wyleczenia bardziej złożonych i zaawansowanych nowotworów. Kanały te mieszczą się bezpośrednio pod powierzchnią aplikatora tak, by zapewnić optymalną kontrolę dozymetryczną w obszarze guza i w obrębie narządów krytycznych [18].

Detektory napromieniono do dawki 2Gy źródłem Ir - 192, na aparacie terapeutycznym flexitron HDR, w warunkach Pracowni Brachyterapii Katowickiego Centrum Onkologii. Aby możliwie jak najbardziej ograniczyć zanik sygnału napromienionych detektorów, w jak najkrótszym czasie po napromienieniu, dokonano odczytu w czytniku laboratoryjnym RA'94 w Zakładzie Fizyki Jądrowej i Jej Zastosowań Uniwersytetu Śląskiego.

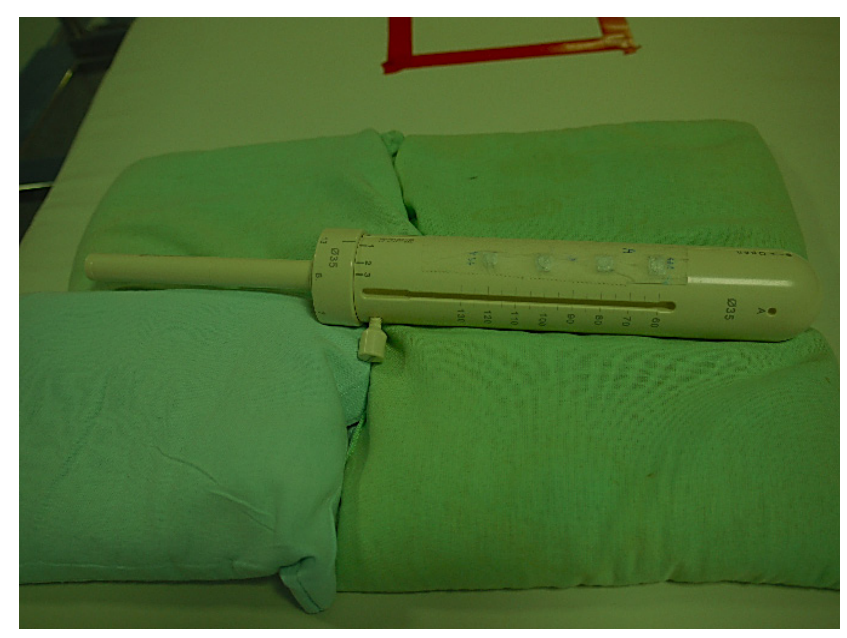

Rycina 2. Wielokanałowy aplikator dopochwowy CT/MR z rozmieszczonymi detektorami w pozycjach: 6omm, 80mm, 100mm, 120mm [fotografia własna].

\section{Detektory MTS}

\section{- Wyniki i dyskusja}

Poza wyżej omówionym wykorzystaniem metody termoluminescencyjnej jej przydatność przejawia się także w zakresie ochrony radiologicznej (dozymetria cząstek i środowiska), biologii jak również na potrzeby datowania w archeologii. Ponieważ nie jest jeszcze tak oczywiste uwzględnienie tej techniki jako narzędzia określania dawki, postanowiono o podjęciu owej tematyki pracy. Najważniejszym etapem pracy była kontrola nad wynikami dawek zebranych dzięki odmiennym metodom a także ich obserwacja w realiach 
podejmowanych algorytmów obliczeniowych. Otrzymane wyniki są zgodne z założeniami pracy. Związek między algorytmami TG-43 i TG-186 stanowi o tym, że są one dla siebie swoistą bazą jednak nie stanowią odpowiedzi na wszystkie problematyczne kwestie planowania leczenia. Algorytm TG-43 zakłada całkowite rozproszenie w wodzie. Nie uwzględnia natomiast warunków rozpraszania w pacjencie oraz otaczającym go środowisku. Decyzje o większej przydatności algorytmu do celów klinicznych podejmuje ośrodek onkologiczny, odpowiedzialny za dobór najefektywniejszej terapii wobec pacjentów.

Porównywano uśredniony z trzykrotnego pomiaru wynik odczytanej dawki z dawką wskazaną przez TPS. Znając odchylenie standardowe wyników odczytów, dawkę kalibracyjną oraz średnią liczbę zliczeń odpowiedniej dla tej dawki, poznaliśmy odchylenia od wartości zmierzonych dawek. Dalsza lokalizacja detektora na aplikatorze, zarówno po stronie „A” jak i „B”, nie wiązała się ze wzrostem dawki.

Wartości dawek zoptymalizowanych na podstawie TG-43 wskazują na średnią dawkę, zmierzoną metodą TLD równą 195,69ะ1,39 cGy oraz średnią wartość dawki pochodzącą z planu leczenia 202,39 cGy. Różnica pomiędzy najwyższą a najniższą zmierzoną dawką wynosi 4,022 cGy natomiast dla dawek zaplanowanych - 4,09 cGy, co można uznać za nieznaczne odchylenia. Największe odstępstwo między dawkami zebranymi z danej lokalizacji sięga 6,57 cGy. Średnio różnica pomiędzy dawką zmierzoną a zaplanowaną to wartość 6,69 cGy.

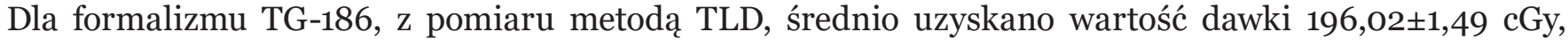
natomiast na drodze TPS - 201,36 cGy. Przy pomiarze metodą TLD, dawki najwyższa i najniższa różnią się o 2,63 cGy, dla wartości zaplanowanych przez system o 4 cGy. Dawki średnie (DTPS, DTLD) dla danego umiejscowienia detektora wahają się w granicach 197,05 - 200,19 cGy. Największa różnica między dawkami zmierzonymi i zaplanowanymi sięga 9,08 cGy, najmniejsza - 4,37 cGy. Do oceny statystycznej posłużono się także współczynnikiem zmienności będącym miarą odchylenia wyników od ich średniej arytmetycznej. Zarówno dla algorytmu TG-43 jak również TG-186 mówimy o małym zróżnicowaniu $(V<20 \%)$.

Najlepszą zgodność wyników, zaobserwowano dla algorytmu TG-186A z racji uwzględnionej gęstości aplikatora w planie leczenia. Największa różnica między dawką z planu i z eksperymentu wyniosła jedynie 1,98cGy. Zmierzone dawki oscylują w przedziale od 193,27 cGy do 201,67 cGy. Różnica między nimi wynosi 8,40 cGy. W odniesieniu do wyników osiągniętych drogą TLD, przedział dawek z TPS obejmuje wartości od 194,5 cGy do 203,63 cGy. Anomalie zarejestrowano na poziomie 9,13 cGy, co wyraża większe odstępstwo niż dla dawek eksperymentalnych. Średnia dawek uzyskanych techniką TLD to wartość $196,86 \pm 1,25 c G y$ natomiast system planowania leczenia wskazywał na 197,87cGy. Wówczas wnioskujemy o najlepszej zgodności pomiędzy parametrami planu leczenia i eksperymentu. Dawki TPS zawierają się w granicach niepewności pomiarowej.

\begin{tabular}{|c|c|c|c|c|c|c|}
\hline Pozycja & $\begin{array}{c}\text { Lokalizacja } \\
{[\mathrm{mm}]}\end{array}$ & $\begin{array}{c}\text { Numer } \\
\text { detektora }\end{array}$ & $\begin{array}{c}\text { Numer } \\
\text { pomiaru }\end{array}$ & $\begin{array}{c}\text { Dawka } \\
\text { zmierzona } \\
\left(\mathrm{D}_{\text {TLD }}\right)[\mathrm{cGy}]\end{array}$ & $\begin{array}{c}\text { Niepewność } \\
\text { pomiarowa } \\
{[\mathrm{cGy}]}\end{array}$ & $\begin{array}{c}\text { Dawka zaplanowana }\left(\mathrm{D}_{\text {TPS }}\right) \\
{[\mathrm{cGy}]}\end{array}$ \\
\hline \multirow{2}{*}{$\mathrm{A}$} & 60 & 45 & 1 & 194,37 & 1,03 & 201,04 \\
\cline { 2 - 7 } & 80 & 24 & 2 & 194,80 & 2,82 & 202,17 \\
\cline { 2 - 7 } & 100 & 84 & 3 & 196,38 & 0,74 & 203,92 \\
\hline \multirow{2}{*}{ B } & 120 & 63 & 4 & 193,93 & 1,93 & 203,01 \\
\cline { 2 - 7 } & 80 & 17 & 5 & 196,00 & 1,83 & 202,77 \\
\cline { 2 - 7 } & 100 & 14 & 6 & 197,96 & 0,37 & 202,75 \\
\cline { 2 - 7 } & 120 & 15 & 8 & 195,46 & 0,62 & 202,39 \\
\hline
\end{tabular}

Tabela 1. Dawki uzyskane metodą TLD wraz z wartościami niepewności pomiarowych, oraz dawki zaplanowane w systemie planowania leczenia TPS, zgodnie z formalizmem TG-43. 


\begin{tabular}{|c|c|c|c|c|c|c|}
\hline Pozycja & $\begin{array}{c}\text { Lokalizacja } \\
{[\mathrm{mm}]}\end{array}$ & $\begin{array}{c}\text { Numer } \\
\text { detektora }\end{array}$ & $\begin{array}{c}\text { Numer } \\
\text { pomiaru }\end{array}$ & $\begin{array}{c}\text { Dawka } \\
\text { zmierzona } \\
\left(\mathrm{D}_{\text {TLD }} \text { [cGy }\right]\end{array}$ & $\begin{array}{c}\text { Niepewność } \\
\text { pomiarowa } \\
{[\mathrm{cGy}]}\end{array}$ & $\begin{array}{c}\text { Dawka zaplanowana }\left(\mathrm{D}_{\text {TPS }}\right) \\
{[\mathrm{cGy}]}\end{array}$ \\
\hline \multirow{2}{*}{$\mathrm{A}$} & 60 & 4 & 1 & 194,94 & 0,67 & 199,42 \\
\cline { 2 - 7 } & 80 & 48 & 2 & 196,30 & 1,08 & 200,61 \\
\cline { 2 - 7 } & 100 & 58 & 3 & 196,79 & 0,96 & 201,57 \\
\cline { 2 - 7 } & 120 & 44 & 4 & 195,35 & 2,34 & 203,31 \\
\hline \multirow{2}{*}{ B } & 60 & 40 & 5 & 197,07 & 2,11 & 202,11 \\
\cline { 2 - 7 } & 80 & 33 & 6 & 197,42 & 1,14 & 202,37 \\
\cline { 2 - 7 } & 100 & 11 & 7 & 195,53 & 1,42 & 199,31 \\
\cline { 2 - 7 } & 120 & 20 & 8 & 194,79 & 2,16 & 201,57 \\
\hline
\end{tabular}

Tabela 2. Dawki uzyskane metodą TLD wraz z wartościami niepewności pomiarowych, oraz dawki zaplanowane w systemie planowania leczenia TPS, zgodnie z formalizmem TG-186.

\begin{tabular}{|c|c|c|c|c|c|c|}
\hline Pozycja & $\begin{array}{c}\text { Lokalizacja } \\
{[\mathrm{mm}]}\end{array}$ & $\begin{array}{c}\text { Numer } \\
\text { detektora }\end{array}$ & $\begin{array}{c}\text { Numer } \\
\text { pomiaru }\end{array}$ & $\begin{array}{c}\text { Dawka } \\
\text { zmierzona } \\
\left(\mathrm{D}_{\text {TLD }} \text { [cGy }\right]\end{array}$ & $\begin{array}{c}\text { Niepewność } \\
\text { pomiarowa } \\
{[\mathrm{cGy}]}\end{array}$ & $\begin{array}{c}\text { Dawka zaplanowana }\left(\mathrm{D}_{\mathrm{TPS}}\right) \\
{[\mathrm{cGy}]}\end{array}$ \\
\hline \multirow{2}{*}{$\mathrm{A}$} & 60 & 32 & 1 & 193,27 & 1,09 & 194,50 \\
\cline { 2 - 7 } & 80 & 74 & 2 & 195,67 & 0,76 & 195,52 \\
\cline { 2 - 7 } & 100 & 31 & 3 & 195,29 & 1,16 & 196,93 \\
\cline { 2 - 7 } & 120 & 59 & 4 & 196,21 & 1,22 & 196,77 \\
\hline \multirow{2}{*}{ B } & 60 & 10 & 5 & 195,37 & 0,97 & 197,35 \\
\cline { 2 - 7 } & 80 & 72 & 6 & 196,58 & 1,75 & 203,63 \\
\cline { 2 - 7 } & 100 & 56 & 7 & 201,67 & 1,60 & 202,07 \\
\cline { 2 - 7 } & 120 & 1 & 8 & 200,79 & 1,41 & 25 \\
\hline
\end{tabular}

Tabela 3. Dawki uzyskane metodą TLD wraz z wartościami niepewności pomiarowych, oraz dawki zaplanowane w systemie planowania leczenia TPS, zgodnie z formalizmem TG-186A.

Odchylenie między dawkami $\mathrm{D}_{\mathrm{TLD}}$ i $\mathrm{D}_{\mathrm{TPS}}$ można zdefiniować również za pomocą parametru $\Delta$, który dzieli różnice dawek przez dawkę zmierzoną.

\begin{tabular}{|c|c|c|c|c|}
\hline & $\mathrm{D}_{\mathrm{TLD}}[\mathrm{cGy}]$ & $\mathrm{D}_{\mathrm{TPS}}[\mathrm{cGy}]$ & $\begin{array}{c}\text { Współczynnik } \\
\text { zmienności (V) [\%] }\end{array}$ & Parametr [\%] \\
\hline TG-43 & 195,69 & 202,39 & 2,38 & 3,42 \\
\hline TG-186 & 196,02 & 201,36 & 1,90 & 2,72 \\
\hline TG-186A & 196,86 & 197,87 & 0,41 & 0,58 \\
\hline
\end{tabular}

Tabela 4. Porównanie dawek TLD uśrednionych ze wszystkich detektorów z dawkami z planów leczenia, oraz zestawienie miar rozbieżności dla eksperymentów uwzględniających formalizm TG-43, TG-186, TG-186A. 


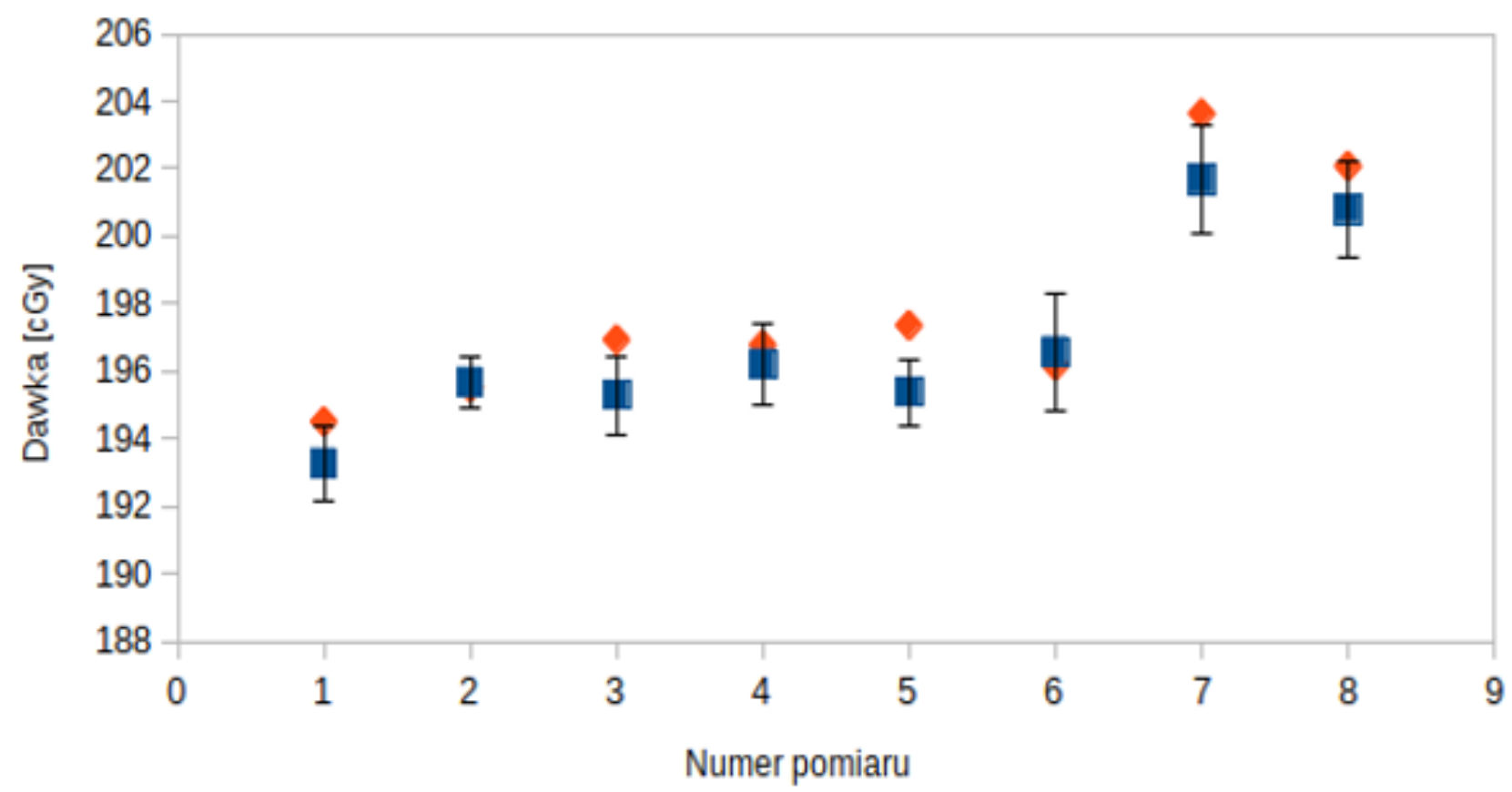

\section{- Dtld $\bullet$ Dtps}

Rycina 3. Porównanie dawek uzyskanych metodą TLD oraz wygenerowanych przez system planowania leczenia TPS, wraz z wynikami niepewności pomiarowych wyrażonych miarą odchylenia standardowego.

\section{Wnioski}

Podsumowując, stosowany algorytm obliczeniowy przekłada się na wartości dawek generowanych przez system planowania leczenia w brachyterapii.

(1) Plany leczenia sformalizowane dzięki TG-43 oraz TG-186 nie dają zbliżonych wyników dawek względem tych, wyznaczonych na drodze eksperymentu.

(2) Dawki eksperymentalne i zaplanowane osiągają najbardziej zbliżone wartości dzięki uwzględnieniu gęstości aplikatora w algorytmie TG-186A.

(3) Równoważność wyników wypracowanych metodą TL i poprzez TPS nie jest możliwa bez ujednolicenia wszelkich istotnych parametrów, mających wpływ na wynik końcowy, w tym wypadku gęstości aplikatora. Idealny system planowania leczenia powinien uwzględniać wpływ aplikatora i niejednorodność tkanek pacjenta przy obliczaniu rozkładu dawki.

\section{Konflikt interesu / Conflict of interest}

Nie występuje / None.

\section{Etyka / Ethics}

Treści przedstawione w artykule są zgodne z zasadami Deklaracji Helsińskiej, dyrektywami EU oraz ujednoliconymi wymaganiami dla czasopism biomedycznych. 


\section{Piśmiennictwo/ References}

[1] Niewiadomski T. Dozymetria termoluminescencyjna w praktyce, Raport IFJ nr 1550/D, 1991.

[2] Furetta C., Weng P.S.: Operational Thermoluminescence Dosimetry. World Scientific Publishing. Co.Pte. Ltd, Singapur, 1998.

[3] Skowronek J. Broszura dla studentów Wydziału Lekarskiego AM: Brachyterapia. Wielkopolskie Centrum Onkologii, Poznań, 2004.

[4] Bulski W., Kawczyńska M., Współczesna brachyterapia, Inżynier i fizyk medyczny. s. 58-63, $2 / 2013$.

[5] Deptała A. Onkologia w praktyce. Warszawa, 2006.

[6] Krzakowski M. Onkologia kliniczna. Tom I, Warszawa, 2006.

[7] Mark J. Rivard M. J., Coursey B. M. et al.: Update of AAPM Task Group No. 43 Report: A revised AAPM protocol for brachytherapy dose calculations, 2004.

[8] Boman L. E., Satherley W. S. T, Schleich N., Paterson D. B.: The validity of Acuros BV and TG-43 for high-dose-rate brachytherapy superficial mold treatments. Brachytherapy 2017.

[9] Granero D, Perez-Calatayud J, Vijande J, et al. Limitations of the TG-43 formalism for skin high-doserate brachytherapy dose calculations. Med Phys 2014;41:021703.

[10] Papagiannis P, Pantelis E, Karaiskos P. Current state of the art. brachytherapy treatment planning dosimetry algorithms. Br J Radiol 2014;87:20140163.

[11] Ouhib Z, Kasper M, Calatayud JP, et al. Aspects of dosimetry and clinical practice of skin brachytherapy. The American Brachytherapy Society working group report. Brachytherapy 2015;14:840e858.

[12] Granero D, Perez-Calatayud J, Vijande J, et al. Limitations of the TG-43 formalism for skin high-doserate brachytherapy dose calculations. Med Phys 2014;41:021703.

[13] Baghani HR, Lohrabian V, Aghamiri MR, Robatjazi M. Monte Carlo Determination of Dosimetric Parameters of a New (125)I Brachytherapy Source According to AAPM TG-43 (U1) Protocol, Arch Iran Med. 2016 Mar;19(3):186-91.

[14] DeWerd LA, Culberson WS, Micka JA, Simiele SJ. A modified dose calculation formalism for electronic brachytherapy sources. Brachytherapy. 2015 May Jun;14(3):405-8

[15] Juan-Senabre XJ, Porras I, Lallena AM, A simple modification of TG-43 based brachytherapy dosimetry with improved fitting functions: application to the selectSeed source, Phys Med. 2013 Jun;29(4):403-11.

[16] Beaulieu L., Tedgren A. C., Carrier J.F., Davis S.D., Mourtada F., Rivard M.J., Thomson R.M., Verhaegen F., Wareing T.A., Williamson J.F.: Report of the Task Group 186 on model-based dose calculation methods in brachytherapy beyond the TG-43 formalism: Current status and recommendations for clinical implementation, 2012.

[17] Ślosarek K. Podstawy planowania leczenia w radioterapii na podstawie skryptu kursu: Praktyczne aspekty współczesnej radioterapii. Polskie Towarzystwo Onkologiczne, Oddział Śląski, Gliwice, 2007.

[18] Broszura: Brachytherapy appliccators and accessories; Nucletron an Elekta Company, 2012. 